Appl. Ent. Zool. 16 (3) : 193-199 (1981)

\title{
Hybridization Experiments on Three Biotypes of the Brown Planthopper, Nilaparvata lugens (Homoptera : Delphacidae) at the IRRI, the Philippines
}

\author{
Kazushige Sōgawa ${ }^{1}$ \\ The International Rice Research Institute, Los Baños, Laguna, Philippines
}

(Received November 25, 1980)

\begin{abstract}
The genetic natures of three biotypes of the brown planthopper, Nilaparvata lugens, which possess different abilities to infest resistant varieties of rice, were studied by analyzing host preference response, feeding ability and nymphal development of the three biotypes and their inter-biotypic hybrid progenies. The results indicated that the biological traits of biotypes 2 and 3 were generally carried over in a recessive or intermediate way when they were hybridized with biotype 1 .
\end{abstract}

\section{INTRODUGTION}

It has recently been recognized that the brown planthopper, Nilaparvata lugens, exists as a complex of populations or demes having different abilities to defeat varietal resistance in rice, which are commonly referred to as biotypes. Presently three biotypes of the brown planthopper, designated biotypes 1, 2 and 3, have been maintained at the IRRI (IRRI, 1976). These biotypes are morphologically identical (Lioumo, 1978), but are clearly distinguished from one another on the basis of their abilities to feed and reproduce on rice varieties with different major genes for resistance to this insect (SōGawa, 1981).

Preliminary genetic studies on brown planthopper biotypes have been attempted in Taiwan and at the IRRI. Cheng and Chang (1979) have reported that the $\mathrm{F}_{1}$ hydrids from the crosses between biotypes 1 and 2 are incapable of wilting Mudgo, but those from biotypes 1 and 3 are capable of wilting ASD 7. These results suggest that biotype 2 is recessive against biotype 1 , and biotype 3 is dominant over biotype 1. IRRI (1978) has reported that biotype 1 is dominant over biotypes 2 and 3 , and biotype 3 is dominant over biotype 2, in the ability of nymphs to survive on resistant varieties with different genes.

The present studies were undertaken to confirm and extend such genetic information about the brown planthopper biotypes.

1 Visiting Scientist from Tropical Agriculture Research Center, Tsukuba, Yatabe, Ibaraki 305, Japan. Present address: Hokuriku National Agricultural Experiment Station, Inada, Joetsu, Niigata 943-01, Japan. 


\section{MATERIALS AND METHODS}

Biotypes 1, 2 and 3 maintained separately as inbred populations at the IRRI were used without further purification. Reciprocal matings were made between biotypes 1 and 2, and biotypes 1 and 3 . The resulting $F_{1}$ progenies were backcrossed to the respective host-resistance-breaking biotypes. The $\mathrm{F}_{2}$ progenies were obtained by crossing the two $F_{1}$ progenies from the reciprocal matings. The $F_{1}$ progenies from the reciprocal crosses between biotypes 2 and 3 were also examined. Each crossing was made in groups with 5 pairs of brachypterous virgin females and males collected at random. All progenies were reared on susceptible IR 24 plants in a greenhouse.

Three IR varieties were mainly used, IR 24 having no resistance gene, IR 26 with a $B p h 1$ gene, and IR 40 with a $b p h 2$ gene. Taichung native 1 (TN 1) and Mudgo were also used instead of IR 24 and IR 26, respectively, in some experiments.

The following characteristics of hybrid progenies were compared with those of their parents: - (1) host preference response, (2) feeding ability, and (3) nymphal development. Experimental procedures are the same as those described in SōgawA (1981).

\section{RESULTS}

\section{Host preference response}

The differences in the behavioral response to IR 40 between biotypes 1 and 3 were conspicuous. Most of the female adults of biotype 1 did not like to settle on IR 40 , and eventually moved to IR 24 within 2 days, while biotype 3 females settled on IR 40. Female adults of $F_{1}, F_{2}$ and backcross progenies from the crosses between biotypes 1 and 3 showed a response similar to that of biotype 1 (Fig. 1). Female adults of $\mathrm{F}_{1}$ progenies from reciprocal crosses between biotypes 2 and 3 also responded similarly to biotype 1, which avoided staying on IR 26 and IR 40 . Results with the hybrids from the crosses between biotypes 1 and 2 were not satisfactory because the parental differences were not significant.

\section{Feeding ability}

Female adults of biotype 1 excreted only $6.5 \mathrm{mg} /$ day/insect of honeydew on IR 26 on the average, while biotype 2 excreted $29.1 \mathrm{mg} /$ day/insect. The $\mathrm{F}_{1}, \mathrm{~F}_{2}$ and backcross progenies from the crosses between biotypes 1 and 2 excreted as little honeydew as did biotype 1 on IR 26, ranging from $5.4 \mathrm{mg}$ to $9.3 \mathrm{mg} /$ day/insect (Fig. 2). Similarly, the female adults of $F_{1}, F_{2}$ and backcross progenies from the crosses between biotypes 1 and 3 excreted significantly less honeydew $(6.5-11.8 \mathrm{mg} /$ day/insect) on IR 40 than did biotype 3 (26.0 mg/day/insect) (Fig. 2). The amount of honeydew excreted by the $\mathrm{F}_{1}$ 's from reciprocal crosses between biotypes 2 and 3 on IR 26 and IR 40 was significantly lower compared with excretion by their upper parents on each resistant variety (Fig. 2).

\section{Nymphal development}

No difference in nymphal growth was observed on IR 26 seedlings between biotypes 1 and 2, and their hybrid $F_{1}$ progenies. Only $10-23.5 \%$ of their nymphs 

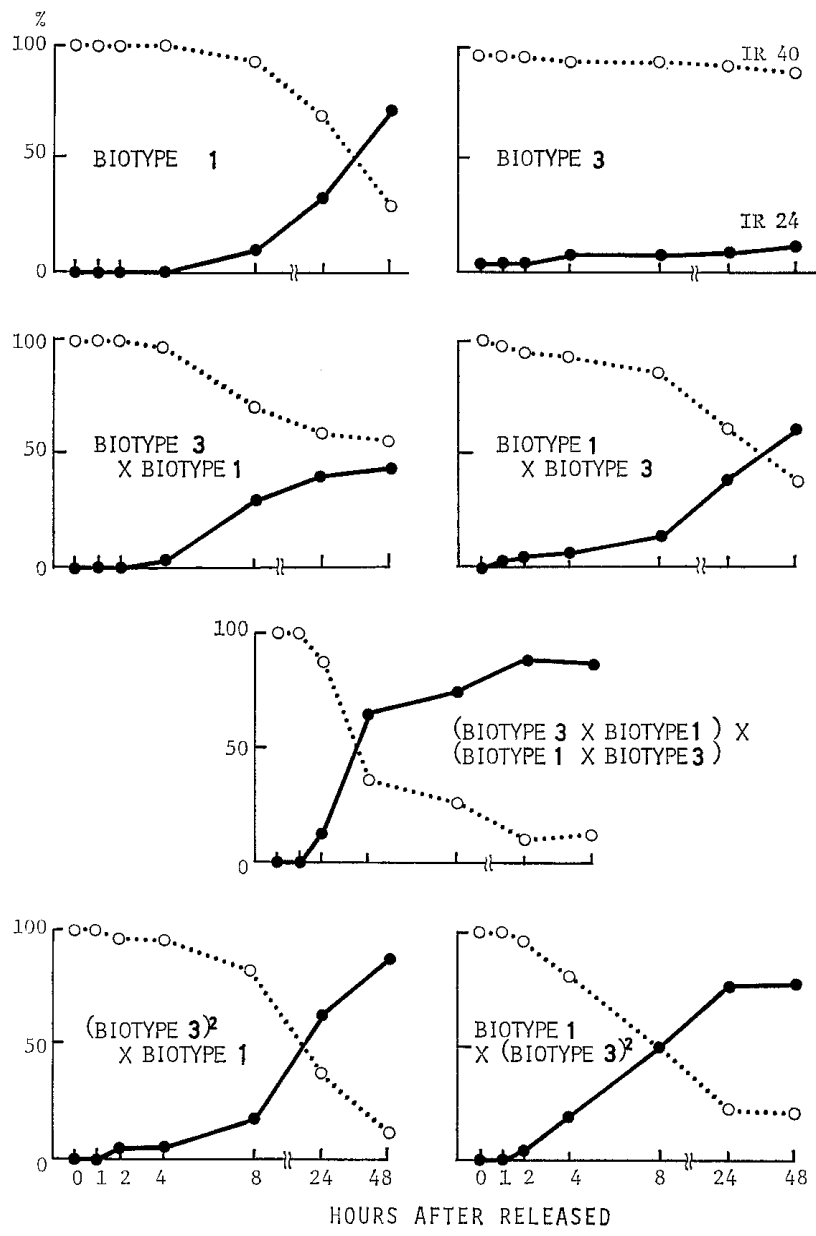

Fig. 1. Host preference reaction of biotypes 1 and 3 , and their hybrid progenies. Vertical scale in each figure indicates percentages of female adults on resistant or susceptible varieties.

emerged to adults on this variety. However, biotype 2 nymphs grew somehow better than biotype 1 nymphs on Mudgo seedlings: nymphal mortality was $30.0 \%$ in biotype 2 , and $68.4 \%$ in biotype 1 . The nymphal mortality of two $\mathrm{F}_{1}$ hybrids on Mudgo was 50 and $65 \%$.

There were distinct differences in nymphal development on IR 40 between biotypes 1 and 3 . All the nymphs of biotype 3 emerged to adults within 15 days on IR 40 , while only $5 \%$ of biotype 1 nymphs reached the adult stage within the same period (Fig. 3). Another $25 \%$ biotype 1 nymphs emerged to feeble and smaller adults taking 18-25 days to complete nymphal development. Seventy per cent of biotype 1 nymphs failed to emerge to adults. About $50-65 \%$ of $\mathrm{F}_{1}$ and $\mathrm{F}_{2}$ progenies from the crosses between biotypes 1 and 3 emerged to adults on IR 40 taking 13-21 days (Fig. 3). The backcross progenies, particularly those having biotype 3 blood on the maternal side, reacted more similarly to biotype 3 than $F_{1}$ (Fig. 3).

Generally, the two $F_{1}$ progenies from the cross between biotypes 2 and 3 exhibited lower nymphal mortality, but longer nymphal periods on IR 26 than their parents (Table 1). On IR 40, the mortality in the $F_{1}$ nymphs was as low as that of biotype 3 , and their nymphal duration was similar to each of their female parent (Table 1). 


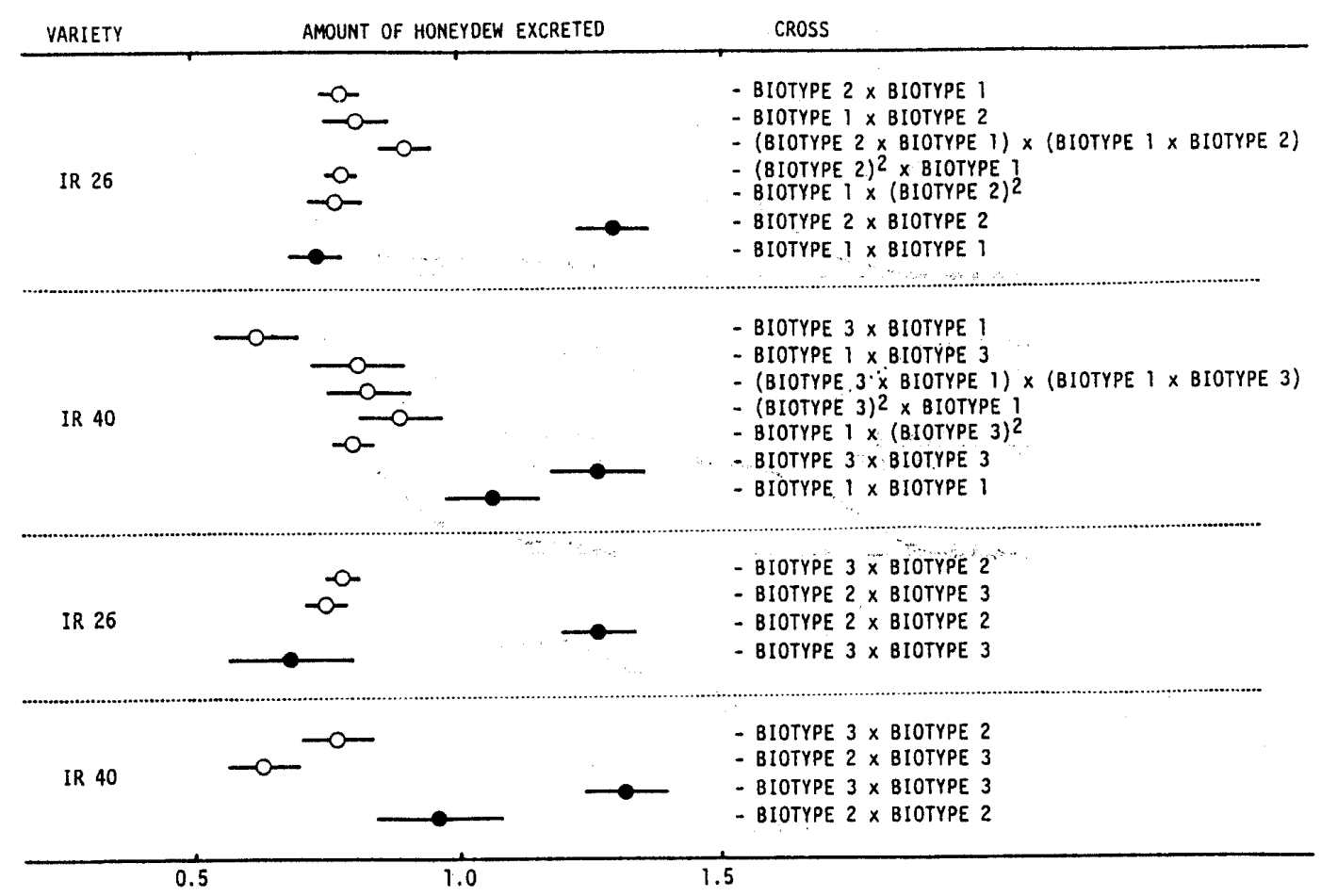

Fig. 2. Honeydew excretion by female adults of biotypes 1,2 and 3, and their hybrid progenies on resistant varieties. Amount of honeydew excreted (mg/day/insect) is transformed to $\log 10$ scale (mean \pm S. E.).

Table 1. Nymphal Development of Biotypes 2 and 3, and Their Hybrid Progenies ON IR 26 AND IR 40 SEEDLINGS

\begin{tabular}{|c|c|c|c|c|}
\hline Variety $\ldots \ldots$ & Cross & $\begin{array}{l}\text { No. nymphs } \\
\text { tested }\end{array}$ & $\begin{array}{l}\% \text { Nymphal } \\
\text { mortality }\end{array}$ & Nymphal duration \\
\hline \multirow[t]{4}{*}{ IR 26} & Biotype $2 \times$ Biotype 2 & 20 & 65.0 & $15.7 \pm 1.8$ \\
\hline & Biotype $3 \times$ Biotype 3 & 17 & 47.1 & $15.3 \pm 1.3$ \\
\hline & Biotype $2 \times$ Biotype 3 & 19 & 31.6 & $19.7 \pm 2.0$ \\
\hline & Biotype $3 \times$ Biotype 2 & 20 & 30.0 & $19.8 \pm 1.8$ \\
\hline \multirow[t]{4}{*}{ IR 40} & Biotype $2 \times$ Biotype 2 & 18 & 27.8 & $16.0 \pm 2.3$ \\
\hline & Biotype $3 \times$ Biotype 3 & 20 & 10.0 & $13.7 \pm 0.3$ \\
\hline & Biotype $2 \times$ Biotype 3 & 18 & 11.1 & $15.2 \pm 1.6$ \\
\hline & Biotype $3 \times$ Biotype 2 & 20 & 0.0 & $13.2 \pm 0.4$ \\
\hline
\end{tabular}

a Mean $\pm 95 \%$ confidential range.

\section{DISGUSSION}

The present experiments showed that some biological characteristics of biotypes 2 and 3 were entirely lost or diluted in hybridization with biotype 1 (Table 2). All the inter-biotypic hybrids excreted as little honeydew on resistant varieties as biotype 1. The improved feeding ability was not restored by backcrossing the hybrid $\mathrm{F}_{1}$ with the respective upper parental biotypes. Likewise, the hybrids between biotypes 1 and 3 , and biotypes 2 and 3 displayed a host preference behavior similar to that of biotype 1. These results indicated the recessiveness of biotypes 2 and 3 


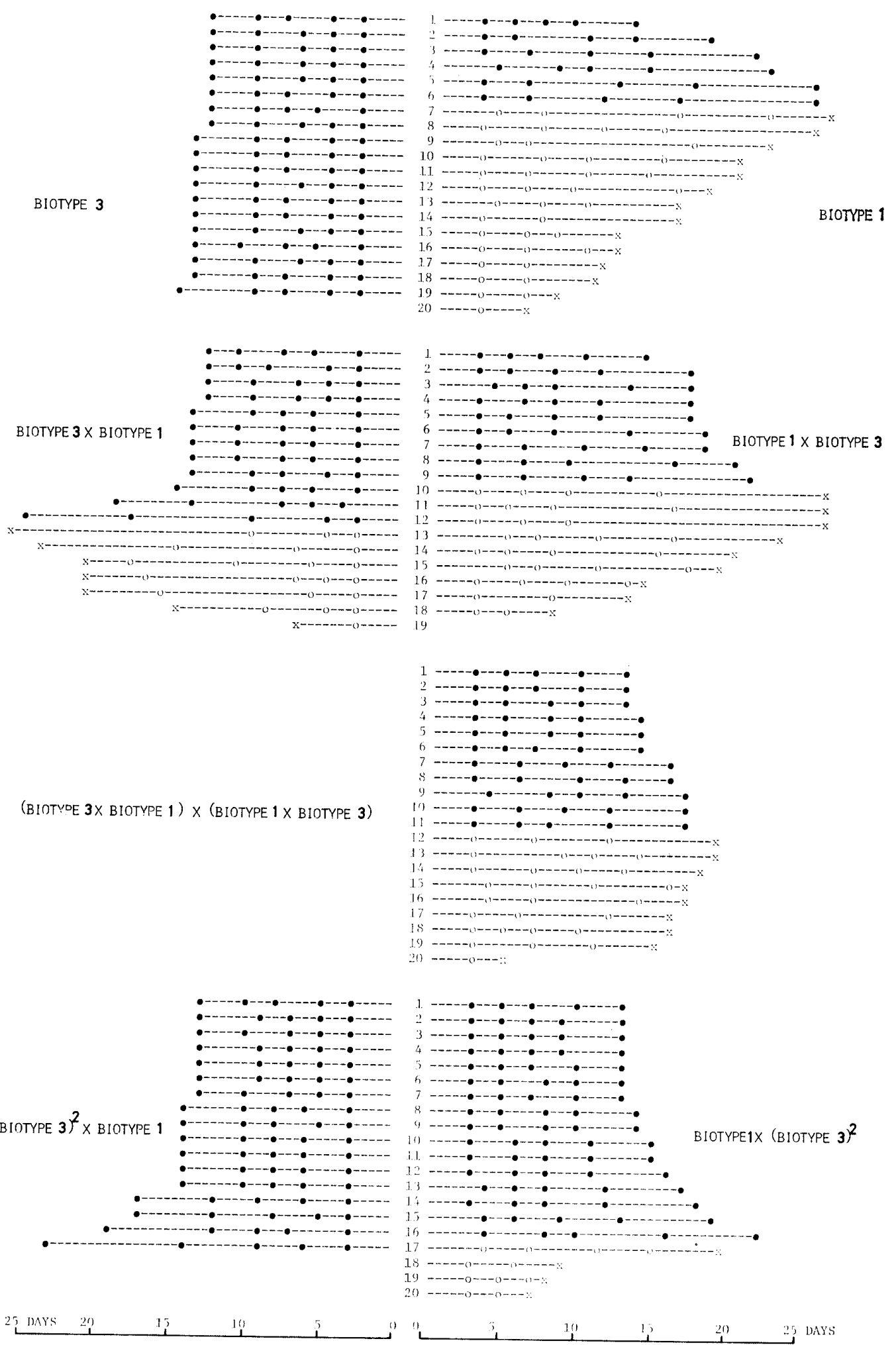

Fig. 3. Individual records of nymphal development of biotypes 1 and 3, and their hybrid progenies on IR 40.

Emerged to adult stage. --- $---\times$ Nymphal stages not completed and died. 
Table 2. Reactions of the $\mathrm{F}_{1}, \mathrm{~F}_{2}$ and Backcross (BC) Progenies for Inter-Biotypia Grossings on Resistant Varieties

\begin{tabular}{|c|c|c|c|c|c|c|c|}
\hline \multirow{2}{*}{ Reaction $^{\mathrm{a}}$} & \multicolumn{3}{|c|}{ Biotypes $1 \times 2$} & \multicolumn{3}{|c|}{ Biotypes $1 \times 3$} & \multirow{2}{*}{$\frac{\text { Biotypes } 2 \times 3}{F_{1}}$} \\
\hline & $\mathrm{F}_{1}$ & $\mathrm{~F}_{2}$ & $\mathrm{BC}$ & $\mathrm{F}_{1}$ & $\mathrm{~F}_{2}$ & $\mathrm{BC}$ & \\
\hline Host preference & $*$ & * & $*$ & 1 & 1 & 1 & 1 \\
\hline Honeydew excretion & 1 & 1 & 1 & 1 & 1 & 1 & 1 \\
\hline Nymphal development & 1 & $*$ & $*$ & $1-3$ & $1-3$ & $3>1$ & $2 / 3$ \\
\hline
\end{tabular}

a $\quad 1=$ Reaction similar to that of biotype 1 .

$1-3=$ Reaction intermediate between that of biotypes 1 and 3 .

$3>1=$ Reaction more similar to that of biotype 3 than of biotype 1 .

$2 / 3=$ Reaction similar to that of biotype 2 or 3 depending on host variety.

$*=$ Not tested because of no significant parental differences.

against biotype 1 in the ability to feed on the resistant varieties, in agreement with earlier IRRI's finding (IRRI, 1978). However, the previous finding that biotype 3 is dominant over biotype 1 (Cheng and GHang, 1979) and biotype 2 (IRRI, 1978) was not confirmed in the present experiments.

It should be, however, pointed out that all the hybrid progenies used in the present experiments were reared on the susceptible variety IR 24, and transferred to the resistant varieties at the adult stage to examine their immediate feeding and preference responses to them. As exhibited in aphid species (e.g. AuclaIr, 1966; LowE, 1973), such an abrupt shift of food plants may influence the expression of the insects genetic ability to accept low phagostimulative resistant varieties.

Possible preconditioning effects by food plants during nymphal stages were overlooked in the nymphal development experiments, where the first instar nymphs were transferred to resistant varieties within a day after hatching on the susceptible variety. In fact these experiments provided somewhat different information on the genetic nature of biotypes. The nymphal growth of hybrid $F_{1}$ progenies from the crosses between biotypes 1 and 3 were seemingly intermediate between that of their parents, indicating an incomplete dominance of the ability of biotype 3 nymphs to grow on resistant varieties. Also the rapid acquisition of the biotype 3 character through a single backcross suggests the involvement of relatively few genes with the biotype 3 character.

Further experiments are needed to clarify whether the indefinite segregations in the $F_{2}$ and backcross progenies are due to the polygenic nature of physiological traits examined or to the genetic heterogeneity of parental biotype populations.

\section{AGKNOWLEDGEMENTS}

The author is deeply grateful to Dr. E. A. HeInrichs, Head of Entomology Department, IRRI, for his interest and encouragement given during the present studies, and to Dr. P. K. Pathak, Postadoctoral Research Fellow, Entomology Department, IRRI, for his valuable suggestions on using the parafilm envelope method for honeydew experiments. The technical assistance of Mr. S. SANGHEZ is also acknowledged.

\section{REFERENCES}

Auglair, J. L. (1966) Dissimilarities in the biology of the pea aphid, Acyrthosiphon pisum (Homoptera : 
Aphididae), on alfalfa and peas in New Mexico. Ann. Ent. Soc. Am. 59 : 780-786.

Gheng, C. H. and W. L. Ghang (1979) Studies on varietal resistance to the brown planthopper in Taiwan. In: Brown planthopper: threat to rice production in Asia. IRRI, Los Baños, Philippines. pp. 251-271.

IRRI (1976) The International Rice Research Institute, Annual Report for 1975, Los Baños, Philippines, 479 pp.

IRRI (1978) The International Rice Research Institute, Annual Report for 1977, Los Baños, Philippines, 548 pp.

LIQUido, N. J. (1978) Morphology, cytology and breeding behavior of Nilaparvata lugens (STÅL) (Delphacidae, Homoptera). M. S. thesis, University of the Philippines, $89 \mathrm{pp}$.

Sōgawa, K. (1981) Biotypic variations in the brown planthopper, Nilaparvata lugens (Homoptera :

Delphacidae) at the IRRI, the Philippines. Appl. Ent. Zool. $16:$ 129-137. 